\title{
Structure and properties of new reversibly crosslinked iPP/LDPE blends
}

\author{
S. Bouhelal ${ }^{1}$, M. E. Cagiao $^{2}$, S. Khallef ${ }^{1}$, D. Benachour ${ }^{1}$, F. J. Baltá Calleja ${ }^{2}$ \\ ${ }^{1}$ LMPMP, Faculty of Engineering, Ferhat Abbas University, Sétif, Algeria \\ ${ }^{2}$ Instituto de Estructura de la Materia, CSIC, Serrano 119, 28006 Madrid, Spain
}

\begin{abstract}
Reversibly crosslinked blends of isotactic polypropylene and low density polyethylene (iPP/LDPE) were prepared in the presence of crosslinking agents using reactive extrusion. The structure and properties of the modified blends were investigated by means of wide-angle X-ray scattering (WAXS), differential scanning calorimetry (DSC), and macro- and micromechanical measurements. The crystallinity of the modified samples (LDPE, iPP and their blends) does not seem to be so much affected by the crosslinking process. Results show that the microhardness of the iPP/LDPE blends notably increases with the iPP content. The micromechanical properties of the modified blends only improve slightly as a consequence of the crosslinking process. In the iPP samples, and also in the iPP/LDPE blends, this process gives rise to the appearance of new, crystalline ethylenic chains, as evidenced by the calorimetric measurements. Furthermore, the impact strength of the modified materials is improved as compared to that of the original ones, while some of the crosslinked blends show a ductile fracture behavior.
\end{abstract}

Keywords: reactive extrusion, reversible crosslinking, microhardness of blends

Correspondence to: F.J. Baltá Calleja (e-mail: embalta@iem.cfmac.csic.es) 


\section{INTRODUCTION}

Polymer properties and applications are strongly affected by crosslinking. Crosslinked polymers are especially adequate for the preparation of high processability fibers, or blow molding films [1]. A particular example is crosslinked polyethylene, PE, very useful in the wire coating and in the preparation of materials capable of shrink under the action of heat $[2,3]$. Crosslinked polyolefins can be obtained, either chemically, by means of an organic peroxide that can decompose, thus creating radicals that react with the polymer chains $[2,4]$, either by direct irradiation of the polymer with a high energy radiation, i.e., electron beams [3, 4], or by $\gamma$-rays [5]. Both methods give rise to the formation of macroradicals capable to produce bonds between the chains by a recombination process [1].

While PE is a polymer easily crosslinked by the above cited methods $[4,6]$, they fail off when applied to isotactic polypropylene iPP. If iPP is either irradiated, or treated with a peroxide, the $\beta$-scission degradation process predominates over the crosslinking reaction $[5,7]$. This is due to the low stability of the tertiary hydrogen atoms of the macroradicals [8]. In fact, the $\beta$-scission degradation originated by the peroxides has been applied to control the molecular weight and the molecular weight distribution in the iPP produced in industrial processes [9, 10]. For this reason, iPP has been considered, until the last decade or so, as a non-crosslinkable polymer. However, in recent years new methods have been developed that allow the preparation of crosslinked iPP $[1,7]$.

In a previous paper [11], we reported a new method developed for the reversible crosslinking of isotactic polypropylene iPP [12]. We investigated as well the properties of the modified materials obtained by using several crosslinking agents. This method is also susceptible to be applied to blends of iPP with high or low density PE, iPP copolymers, their blends with elastomers, etc [13]. Moreover, the starting polymers do not need to be only freshly prepared, but can also be recycled, restored, etc [11-13]. As polyolefins are among the polymers most used worldwide, the possibility of solving the problems related with their recovery and recycling is indeed very attractive.

Consequently, we have extended our reversible crosslinking method [11-13] to low density polyethylene (LDPE) samples, and also, to several iPP/LDPE blends with different composition. The present paper deals with the preparation and characterization of these reversibly crosslinked materials. 
As it was indicated [11], the materials to be used in the crosslinking process are: iPP and/or LDPE, an organic peroxide, sulfur $\mathrm{S}$, an accelerator, and potassium persulfate. The "crosslinking agent" is constituted by the peroxide, sulfur and the accelerator. All these materials have been mixed by extrusion. However, any other transformation process currently used in the thermoplastics industry can be used, as, for instance, blow, injection or compression molding. Therefore, the modified polymers can be used to manufacture a number of articles.

The principle of the crosslinking reaction has been already explained [11]. Basically, it consists in creating macroradicals at such a rate that they can act immediately on sulfur, before the termination reaction takes place. The crosslinking process is a chemical reaction of homolytic type. As a first step, the peroxide decomposition (initiation reaction) gives rise to the formation of macroradicals with a very short lifetime. Then, the sulfur atoms link the chains (coupling reaction) by forming a tridimensional network. The bridges linking the chains can be: single sulfur atoms, polysulfides, i.e., $-(\mathrm{S})_{\mathrm{x}^{-}}$, or even cyclic S-compounds. Accelerators increase the sulfur activation rate, in such a way that the macroradicals' creation and their coupling reaction with the sulfur take place simultaneously. Thus, it is possible to achieve an optimum crosslinking degree for each formulation. The potassium persulfate makes possible to regulate, in a more efficient way, the macroradicals' lifetime. More details concerning the experimental procedure are given in [12] and [13]

From the foregoing, it is clear that blend composition has to be adjusted taking into account the crosslinking degree to be obtained. This, in turn, is closely related to the radical peroxide efficiency, and its activation rate. For this reason, in every experiment it is necessary to take into consideration both the transformation temperature, and the specific characteristics of the extrusion equipment to be used [11].

The aims of the present work are two-fold:

1. The preparation of crosslinked iPP, LDPE and their blends in different proportions.

2. To examine the influence of the crosslinking process in the structure and properties of the modified materials. 


\section{EXPERIMENTAL}

\section{Materials}

The materials used in this investigation were the following:

Isotactic polypropylene (iPP) Sabic-Vestolen 9000-67404: supplied by Chemische Werke Hüls, Germany. Low density polyethylene (LDPE) B21 sak: supplied by ENIP, Skikda, Algeria.

Dicumyl peroxide (DCP) (96\% activity): supplied by NORAX. Sulfur, (S) (vulcanizing agent for rubber): supplied by Wuxi Huasbeng Chemical Additives Factory, China. Potassium persulfate: supplied by Innochem, Belgium.

The three accelerators used were: "Super accelerator 500" (tetramethyl thiuram monosulphide, TMTM); "Super accelerator 501" (tetramethyl thiuram disulphide TMTD); and "Quick accelerator 200" (mercaptobenzothiazole disulphide, MBTS). They were supplied by Rhône-Poulenc, France.

The peroxide, the sulfur, and the accelerators constitute the "crosslinking agents".

\section{Blend preparation}

For the preparation of the blends, the sulfur concentration was always equal to that of the peroxide. The amount of sulfur and peroxide was 0.2 or 0.4 wt $\%$. In all cases, the accelerator was $1 / 4$ of the sulfur and peroxide concentration. The composition of the samples discussed in the present study is indicated in Tables 1.1 and 1.2.

The iPP and/or the LDPE samples, the crosslinking agent and potassium persulfate were first mixed in the solid state, using a small quantity of vegetal oil, to wet and improve the dispersion of the fine powder of the different components within the granules of, both, iPP and LDPE. Thereafter, the obtained mixture was inserted into a single screw laboratory extruder (Prolabo 1989) with the following characteristics: L/D $=20$; screw diameter $=25 \mathrm{~mm}$; screw speed $=60$ turns $/ \mathrm{min}$. The residence time was about $3 \mathrm{~min}$. The temperature profile used for the three stages was:

Feed zone $=155^{\circ} \mathrm{C}$; compression zone $=180^{\circ} \mathrm{C}$; homogenization zone $=200^{\circ} \mathrm{C}$. Every extrusion cycle was repeated twice, in order to achieve a homogeneous blend. 


\section{Techniques}

The samples were characterized by using wide-angle X-ray scattering (WAXS), differential scanning calorimetry (DSC), microhardness measurement, tensile stressstrain experiments, and impact strength tests.

The WAXS study was performed using a Seifert diffractometer (reflection mode). The working conditions were as follows: voltage: $40 \mathrm{kV}$; intensity: $35 \mathrm{~mA}$; angular range: $5-30^{\circ}(2 \theta)$; scan rate: $0.01 \%$; slits: $0.3,0.2$. The crystallinity $\alpha_{r X}$ of every sample was calculated from the ratio of the area corresponding to the crystalline peaks to the total area of the diffractogram.

Thermal analysis was performed in a Perkin-Elmer differential scanning calorimeter DSC-4, in an inert $\mathrm{N}_{2}$ atmosphere. The temperature range studied was $45-$ $220^{\circ} \mathrm{C}$. The heating rate was $20^{\circ} \mathrm{C} / \mathrm{min}$. Typical sample weights were $5-10 \mathrm{mg}$. The crystallinity measured by calorimetry, $\alpha_{D S C}$, was derived from the melting enthalpy obtained by DSC using the expression: $\alpha_{D S C}=\Delta H_{m} / \Delta H_{m}{ }^{\infty}$; here, $\Delta H_{m}$ and $\Delta H_{m}{ }^{\infty}$ are the experimental melting enthalpy and the melting enthalpy for an infinitely thick crystal, respectively.

Microhardness $H$ was measured at room temperature using a Leitz tester, adapted with a square-based diamond indenter [14]. The $H$-value was derived from the residual projected area of indentation according to the expression: $H=k P / d^{2}$, where $d$ is the length of the impression diagonal in meters, $P$ the contact load applied in $\mathrm{N}$ and $k$ is a geometrical factor equal to 1.854 . Loads of $0.25,0.5$ and $1 \mathrm{~N}$ were used. The loading cycle was $0.1 \mathrm{~min}$. The $H$-value was derived from the average of $8-10$ indentations.

Tensile stress-strain experiments were performed in dumb-bell samples prepared in a non-isotropic ASTM mold, according to the ASTM norm D 638. The crosshead speed used in the tensile experiments was $5 \mathrm{~mm} / \mathrm{min}$.

The impact strength test was carried out in a device equipped with a control of absorption energy. Specimens were prepared by compression molding. Notched $(1 / 10$ deep) specimens were tested by the Izod strength method. Measurements were carried at room temperature according to the ASTM D 180 norm., being the specimen thickness and width 3 and $9 \mathrm{~mm}$, respectively. Resiliences $a_{k}\left(\mathrm{~J} / \mathrm{m}^{2}\right)$ and energies of absorption $(\mathrm{J})$ were obtained using a hammer of $7 \mathrm{~J}$. 


\section{RESULTS}

\section{Wide-angle $\mathrm{X}$-ray diffraction}

WAXS patterns taken on the LDPE samples before and after crosslinking, not shown here, are typical for the orthorhombic form of polyethylene (see fig. 3.3 in [15]). In addition, the crystallinity $\alpha_{r X}$ values remain practically constant $\left(\alpha_{r X}=0.36-0.40\right)$. These results indicate that the crosslinking process does not affect the crystalline structure of the material.

We present here a brief summary of the behavior of the crosslinked iPP samples, previously described [11], in order to compare their properties with those exhibited by the LDPE samples, and by the blends of both polymers, crosslinked by using the same agents.

The WAXS diagrams of all iPP samples are characteristic of the monoclinic $\alpha$ form of isotactic polypropylene [16]. Fig. 1 shows the diffractograms of the pristine iPP and one of the crosslinked iPP samples (the composition is shown in Table 1.1). All the crosslinked samples have crystallinity values $\alpha_{r X}$ that are slightly lower than that of the non-modified iPP (see Table III in [11]). In addition, the WAXS patterns of the crosslinked iPP samples exhibit a new, small intensity reflection at about $23.8^{\circ}(2 \theta)$ [11] (see Fig. 1). This reflection, indicated by an arrow, can be related to the (200) planes in PE [15]. Moreover, the (111) reflection, appearing at about $21^{\circ}(2 \theta)$ in the non-modified iPP, is slightly shifted to higher angles, nearly coinciding with the (110) reflection of $\mathrm{PE}$, at $21.55^{\circ}(2 \theta)$ [15]. All the crosslinked iPP samples (not shown here for the sake of clarity) behave in the same way as sample 1 . Their WAXS patterns only differ in the relative intensity of some diffraction peaks.

Fig. 2 illustrates the WAXS patterns of the original and one of the crosslinked iPP/LDPE 50/50 blends (sample IIA, the composition is given in Table 1.2). It can be seen that the diffractograms of the as-prepared and the crosslinked blend exhibit the characteristic reflections of, both, LDPE and iPP. The other crosslinked iPP/LDPE $50 / 50$ blends (not shown here) look quite similar to the one depicted in Fig. 2. Indeed, the crosslinking process seems mainly to affect the relative intensity of some reflections. The same behavior can be observed in the WAXS patterns of the crosslinked blends with compositions iPP/LDPE 30/70 and 70/30. It is interesting to note that, whereas the non-modified blends iPP/LDPE 50/50 (see Fig. 2) and 70/30 
exhibit a small reflection at $16.1^{\circ}(2 \theta)$, characteristic of the $\beta$-form of the iPP, this reflection does not appear in the corresponding crosslinked blends.

On the other hand, the crystallinity values $\alpha_{r X}$ of the crosslinked material remain very close to that of the original iPP/LDPE 50/50 blend (see Table 2.2). This also applies to the other PP/LDPE blends with compositions $30 / 70$ and 70/30. The crystallinity data $\alpha_{r X}$ derived for these blends are listed in Tables 2.1 and 2.3, respectively.

\section{Differential scanning calorimetry}

The thermograms of the original and the crosslinked LDPE samples, not shown here, are identical. The crystallinity values $\alpha_{D S C}$ derived from them remain practically constant after the crosslinking process $(0.38-0.40)$. The crystal thickness $l_{c}$, derived from the melting point $T_{m}$ by using the Thomson-Gibbs equation, remains also constant $\left(l_{c}=7.7-8.1 \mathrm{~nm}\right)$.

Fig. 3 shows the thermograms of the original iPp, and those of two crosslinked iPP samples (1 and 4). The composition is indicated in Table 1.1. Here, one observes a new, low temperature melting peak (indicated by an arrow), appearing in the crosslinked iPP samples. The rest of crosslinked iPP samples show similar thermograms. The appearance of a low $T_{m}$ peak, as pointed out in [11], may be due to the presence of PE chains, eventually originated by the reaction of, both, the peroxide and the potassium persulfate on some of the tertiary carbon atoms of the iPP. Table III in [11] collects the melting temperatures $T_{m}$ corresponding to the different peaks for each sample.

The thermodynamic crystal size $l_{c}$ has been derived for each maximum by means of the well known Thomson-Gibbs equation:

$$
T_{m}=T_{m}^{0}\left[1-\left(2 \sigma_{e} / \Delta H_{m}{ }^{\infty} l_{c}\right)\right.
$$

where $\sigma_{e}$ is the surface free energy and $T_{m}{ }^{0}$ is the equilibrium melting point of each component. Table III [11] lists, besides the $l_{c}$ values, the melting enthalpies $\Delta H_{m}$ and the crystallinities $\alpha_{D S C}$ for, both, iPP and PE. We have used the following values for this calculation: a) for the iPP component, we have taken $\Delta H_{m}{ }^{\infty}=207.33 \mathrm{~J} / \mathrm{g}[17], T_{m}{ }^{0}=$ $460.7 \mathrm{~K}[17]$, and $\sigma_{e}=100 \mathrm{erg} / \mathrm{cm}^{2}[18] ; \mathrm{b}$ ) for the PE component, we have used $\Delta H_{m}{ }^{\infty}$ 
$=293.86 \mathrm{~J} / \mathrm{g}[17]$ and $T_{m}{ }^{0}=414.6 \mathrm{~K} \mathrm{[17]}$; in addition, for the surface free energy $\sigma_{e}$ of the $\mathrm{PE}$, we have taken the value of $79 \mathrm{erg} / \mathrm{cm}^{2}$ [19]. This value probably represents an upper limit. In fact, according to our results, $\sigma_{e}$ on linear PE samples depends on the molecular weight. Thus, for the PE samples studied in [19], the surface free energy varies between 79 and $91 \mathrm{erg} / \mathrm{cm}^{2}$. In addition, the melting temperature obtained in our work for the first maximum appearing in the thermograms of the crosslinked iPP samples is $117-118^{\circ} \mathrm{C}$. This relatively low value suggests that the $\mathrm{PE}$ originated during the crosslinking process is not linear, but branched, and/or has a low molecular weight.

Figs. 4 and 5 show the scans corresponding to the DSC study of the iPP and LDPE blends with compositions 50/50 and 70/30. For the sake of clarity, in both figures only the thermograms of the original blends and two crosslinked samples are shown. The specific compositions are shown Table 1.2. It is worth noting that, in the thermograms of the crosslinked blends, the melting peak of the LDPE is wider than in the non-modified ones (figs. 4 and 5). The 30/70 iPP/LDPE blends, not shown here, behave similarly. This means that the crystal thickness $l_{C P E}$ distribution is more heterogeneous in the crosslinked materials. In addition, the $l_{C P E}$ average value increases slightly (Tables 2.1 to 2.3). On the other hand, the area of the LDPE melting peak notably increases in all the crosslinked samples, as compared to the non-modified ones. For instance, in the non-modified iPP/LDPE blends with compositions 30/70, 50/50 and $70 / 30$, the ratio of the area calculated for the LDPE melting peak is 77.4, 49.7 and 39.5 $\%$, respectively. However, in the crosslinked iPP/LDPE blends, the area of the LDPE melting peak varies between 79 and $81 \%$ (series VI), 66 and $69 \%$ (series II), and 49 and $58 \%$ (series IV). Moreover, in the thermograms of all the crosslinked iPP/LDPE blends, together with the main melting peak of the LDPE at about $111-113^{\circ} \mathrm{C}$, a shoulder appears at about $118-120^{\circ} \mathrm{C}$ (see Fig. 4, blends iPP/LDPE 50/50, and Fig. 5, blends iPP/LDPE 70/30). Nevertheless, the iPP melting peak in the crosslinked samples looks quite similar to the one in the non-modified ones (Figs. 4 and 5).

The crystallinity $\alpha_{P E}$ derived from the DSC study increases in all the crosslinked blends, independently of the composition, in relation to the non-modified ones (see Tables 2.1 to 2.3). On the contrary, $\alpha_{P P}$ does not vary (blends iPP/LDPE 30/70, see Table 2.1), or shows only a small decrease (blends 50/50 and 70/30, see Tables 2.2 and 2.3). Total crystallinities $\alpha_{r X}$ and $\alpha_{D S C}$, derived from both methods, show quite similar values. 


\section{Mechanical properties}

The crosslinking process does not seem to influence the microhardness, $H$, of the LDPE samples, being $H=20-21 \mathrm{MPa}$ for all samples. However, crosslinked iPP samples show hardness values lower than the non-modified material, except for sample 5 , in which hardness slightly increases (see Table III in [11]).

Tables 2.1 to 2.3 include the microhardness $H$ values measured for all the blends studied. It can be seen that the crosslinked iPP/PE blends present $H$ values that are identical (blends iPP/PE 30/70, Table 2.1) or even higher (blends iPP/LDPE 50/50 or 70/30, see Tables 2.2 and 2.3) than those shown by the non-modified material.

The microhardness of the blends as a function of iPP content is plotted in Fig. 6. Here, the black symbols represent the data of the unmodified material, and the white ones, those of the crosslinked blends. As it was above told, most of the modified blends have higher $H$-values that their original counterparts. Two straight lines showing the additivity behavior of samples are drawn in Fig. 6: the straight line 1 corresponds to the unmodified materials, and the straight line 2 , to the crosslinked blends. Similarly, curve 3 indicates the real behavior of the original blends, and curve 4 , that of the modified samples. From the plot, it is clear that neither the unmodified nor the crosslinked blends obey the additivity law [14]:

$$
H_{\text {blend }}=H_{P E} \Phi+H_{P P}(1-\Phi)
$$

where $\Phi$ and $(l-\Phi)$ are the weight fractions of LDPE and iPP, respectively.

On the other hand, the macroscopic mechanical properties obtained from the tensile stress-strain study are listed in Table 2.4. They include the elastic modulus, and the stress, strain and energy at break for all the crosslinked blends.

The impact strength of the crosslinked LDPE samples, not shown here, is improved about 1.5-2.4 times as compared to that the original material (except in sample X4, compositions indicated in Table 1.1). The same effect, but much stronger, is also observed for the crosslinked iPP/LDPE 30/70 blends. From Table 2.1, it can be deduced that the crosslinking process increases the impact strength of these samples until 10 times (see, for instance, sample VI5), as compared to the untreated material. However, in the iPP/LDPE 50/50 and 70/30 blends the crosslinking effect upon the impact strength is much smaller, crosslinked samples having impact strength values between 1.3 and 2.7 times higher than the non-modified counterparts (see Table 2.2 and 2.3). The type of fracture shown by the crosslinked blends is ductile in some cases, i.e., samples VI5 and VI6 (see Fig. 7b), but brittle in others, i.e., samples IV5, IV6, IIE (see 
Fig. 7a) and IIF (compositions are indicated in Table 1.2). The crosslinked blends that present higher impact strength values are, at least in some cases, those showing a ductile fracture.

\section{DISCUSSION}

\section{$\underline{\text { LDPE and iPP samples }}$}

The above WAXS and DSC results indicate that the melting point $T_{m}$, the crystallinity $\alpha$ (derived by both methods, DSC and WAXS), the crystal thickness $l_{c}$ and the microhardness $H$ values remain practically the same for all the LDPE samples before and after crosslinking. However, the impact strength of the crosslinked samples is improved (until 2.4 times in sample X1, compositions are indicated in Table 1.1) as compared to that the original material. The character of ductile fracture of the samples also increases in the crosslinked LDPE.

On the contrary, from Table III in [11], it is clear that the crosslinking affects the iPP samples, the crosslinked samples showing $\alpha$ and $H$ values slightly lower than the non-modified counterpart. Most interesting, however, is the fact that the crosslinking process gives rise to the appearance of a certain amount of PE. This is why, in the diffractograms of the crosslinked iPP samples (Fig. 1), a new reflection can be seen at $21^{\circ}(2 \theta)$, which is related to the (200) planes of PE [15]. The ethylenic chains are also responsible for the appearance of a low temperature peak, indicated by an arrow, in the thermograms of the crosslinked iPP (Fig. 3). The area of this new peak represents from 25 to $29 \%$ of the total area of each thermogram, depending on the sample [11]. FTIR studies performed on these samples [20], but not shown here, confirm the presence of ethylenic chains in the crosslinked iPP. The two bands appearing at 720 and $730 \mathrm{~cm}^{-1}$ in the crosslinked iPP are attributed to the ethylenic chains created during the crosslinking process. These bands are characteristic of the rocking mode of the $\left(-\mathrm{CH}_{2}-\right)_{\mathrm{n}}$ sequences when $n \geq 4$ [21]. In addition, the ratio of the intensities between the bands at 2920 and $2950 \mathrm{~cm}^{-1}$, attributed to the $\mathrm{CH}_{2}$ and $\mathrm{CH}_{3}$ antisymmetric stretching modes [22], respectively, increases in the all crosslinked iPP as compared to the original one [20]. Moreover, in the modified iPP a band appears at $2849 \mathrm{~cm}^{-1}$, related to the $\mathrm{CH}_{2}$ symmetric stretching mode [22], which is not visible in the pristine iPP [20]. 
The modified samples have impact strength values considerably higher than the original iPP, showing a ductile fracture instead of the brittle one characteristic of the non-modified material (see [11]).

\section{iPP/LDPE blends}

The crystallinity values (both $\alpha_{r X}$ and $\alpha_{D S C}$ ) of the iPP/LDPE blends remain practically identical to the values shown by the non-modified materials (see Tables 2.1 to 2.3). The Hardness $H$ is slightly improved in the crosslinked blends, especially in those with iPP/LDPE 50/50 and 70/30 composition. (See Tables 2.1 to 2.3).

As we have shown in the preceding section, none of the blends included in this study obey the additivity law. It is well known that the hardness of a semicrystalline polymer can be expressed as: $H=H_{c} \alpha+H_{a}(l-\alpha)$ [14]. Here, $H_{c}$ and $H_{\alpha}$ are the hardness values of the crystalline and amorphous phase, respectively. On the other hand, the crystalline hardness $H_{c}$ can be expressed as [14]:

$$
H_{c}=H_{0} /\left(1+b / l_{c}\right)
$$

In this equation, $H_{0}$ represents the hardness of an infinitely thick crystal, $l_{c}$ the crystal thickness, and $b$ is a parameter relating the surface free energy, $\sigma_{e}$, of the crystals, and the energy necessary to deform the crystals plastically, being $b=\sigma_{e} / \Delta h$. As it can be seen from Tables 2.1 to 2.3 , after the crosslinking process, the crystal thickness $l_{c}$ of, both, iPP and LDPE, remains practically the same as compared to the original LDPE and iPP material. Hence, the deviation of the hardness of the blends from the values predicted by the additivity law could be originated by an increase of the $b$ parameter, indicating that the surface free energy $\sigma_{e}$ of the crystals increases in the blends; in other words, that the crystal surface in the blends is more disordered than in the homopolymers iPP and LDPE, as it has been shown to occur in PE/iPP gel blends [23].

The largest difference between the as-prepared and the crosslinked materials arise from their thermal behavior. As mentioned above, whereas in the crosslinked blends the iPP melting peak retains more or less its shape, as compared to the noncrosslinked ones, the LDPE peak seems to be more affected. Indeed its width increases, and also, it shows a shoulder at $118-120^{\circ} \mathrm{C}$, together with the LDPE melting peak at 
$111-113^{\circ} \mathrm{C}$. In addition, the area of the LDPE melting peak increases in all the crosslinked blends, as compared to the non-modified ones. Probably, these effects are related to the crosslinking process of the iPP component, which, as it happens in case of crosslinked pure iPP samples, gives rise to the formation of a certain amount of PE that would add to the LDPE initially present in the blends. The generation of the ethylenic chains during the crosslinking process of the iPP has been already explained in some detail [11]. The oxy-radicals of the peroxide could eventually attack the tertiary carbons of the iPP, which, through the formation of a double bond, might react with the $\mathrm{H}$ atom of the methyl side groups. The process would finally give rise to the formation of branched ethylenic chains, which should to be responsible for the melting peak visible at $117-118^{\circ} \mathrm{C}$ in the thermograms of the modified iPP [11].

In a similar way, in the crosslinked iPP/LDPE blends, the shoulder appearing on the high temperature side of the PE melting peak and the increase in the proportion of the area of the same melting peak are probably due to the newly created PE chains. These chains are thought to be responsible for the improvement of the impact strength in all the modified samples, this effect being much stronger in the PP/LDPE 30/70 blends. This improvement is accompanied by a ductile behaviour in some of the sampled studied.

The mechanical properties of the crosslinked blends are listed in Table 2.4, including the values found for the elastic modulus $\mathrm{E}$, and the stress, strain and energy at break for the three series.

Fig. 8 shows the plot of the elastic modulus, E (see Table 2.4), as a function of the microhardness $\mathrm{H}$ (see Tables 2.1 to 2.3) for the crosslinked blends. One can derive the relation $\mathrm{E} / \mathrm{H}$ for every series of crosslinked blends. Thus, for the blends with composition iPP/LDPE 30/70, is $\mathrm{E} / \mathrm{H}=13$, a value close to that derived by Struik [24] and Flores et al [25], which found $\mathrm{E} / \mathrm{H}=10$ for $\mathrm{PE}$ samples with different morphologies. However, in iPP/LDPE 50/50 and 70/30 blends, we find $\mathrm{E} / \mathrm{H}=17-19$. It appears that the relation between the elastic modulus and the microhardness increases with the proportion of the iPP in the blends. 


\section{Final remarks}

In conclusion, the method initially developed to reversibly crosslink the iPP has been shown to be also applicable to iPP/LDPE blends having different composition by using a reactive extrusion method. The modified materials retain their level of crystallinity. However, their micromechanical characteristics slightly improve. The hardness of the blends increases with their iPP content. As a consequence of the crosslinking process, a certain amount of PE chains are formed at expenses of the iPP initially present in the blends, as it has been demonstrated from the DSC analysis. These PE chains are probably originated by a process similar to the one explained for the case of pure iPP samples, being responsible for the improved impact strength found in the crosslinked samples, and for the ductile behavior shown by some of them.

\section{Acknowledgments}

Thanks are due to the Drs. A. Bartolotta and G. Di Marco, from the "Istituto per i Processi Chimico-Fisici", Sez. Messina (CNR, Messina, Italy), who have performed the FTIR study. Grateful acknowledgement is due to the MEC, Spain (Grant FIS200401331) for the generous support of this investigation. 


\section{References}

1. F. Romani, R. Corrieri, V. Braga, F. Ciardelli, Polymer, 43, 115-1131 (2002).

2. H. A. Khonakdar, J. Morshedian, M. Mehrabzadeh, U. Wagenknecht, S. H. Jafari, European Polym. J., 39, 1729-1734 (2002).

3. H. A. Khonakdar, S. H. Jafari, U. Wagenknecht, D. Jehnichen, Radiat. Phys. Chem., 75, 78-86 (2006).

4. H. A. Khonakdar, S. H. Jafari, M. Taheri, U. Wagenknecht, D. Jehnichen, L. Häussler, J. Appl. Polym. Sci., 100, 3264-3271 (2006).

5. W. K. Busfield, European Polym. J., 17, 333-340 (1981).

6. J. P. Mercier, E. Maréchal, Chimie des Polymères (Traité des Materiaux, Vol. 13) ; Presses Polytechniques Romandes: Lausanne, 1996; Chapter 9. pp. 353-391.

7. J. Kubo, K. Otsuhata, S. Ikeda, T. Seguchi, J. Appl. Polym. Sci., 64, 311-319 (1997).

8. H.-G. Fritz, B. Stöhrer, Int. Polym. Proc., 1, 31 (1986).

9. F. Berzin, B. Vergnes, S. V. Canevarolo, A. V. Machado, J. A. Covas, J. Appl. Polym. Sci., 99, 2082-2090 (2006).

10. F. Berzin, B. Vergnes, L. Delamare, J. Appl. Polym. Sci., 80, 1243-1252 (2001).

11. S. Bouhelal, M. E. Cagiao, D. Benachour, F. J. Baltá Calleja, J. Appl. Polym. Sci., 103, 2968-2976 (2007).

12. U. S. Patent No. $6,987,149$.

13. U. S. Patent No. 7,241,844.

14. F. J. Baltá Calleja, S. Fakirov. Microhardness of Polymers (Solid State Science Series); Cambridge University Press: Cambridge, 2000. p.11.

15. F. J. Baltá Calleja, C. G. Vonk. X-ray Scattering of Synthetic Polymers (Polymer Science Library 8). A. D. Jenkins, Ed. Elsevier: Amsterdam, 1989. Chapter 3, p. 94.

16. J. Karger-Kocsis, Ed. Polypropylene (Vol. 1: Structure, Blends and Composites); Chapman and Hall: London, 1995.

17. B. Wunderlich. Macromolecular Physics (Vol. 3: Crystal Melting); Academic Press: New York, 1980. p.48 
18. A. Flores, J. Aurrekoechea, R. Gensler, H. H. Kausch, F. J. Baltá Calleja, Colloid Polym. Sci., 276, 786 (1998).

19. F. J. Baltá Calleja, C. Santa Cruz, R. K. Bayer, H. G. Kilian, Colloid Polym. Sci., 268, 440 (1990).

20. A. Bartolotta and G. Di Marco (unpublished results).

21. L. J. Bellamy. The Infrared Spectra of Complex Molecules. Methuen: London/Wiley: New York, 1964; Chapter 2, pp. 27-29.

22. L. J. Bellamy. The Infrared Spectra of Complex Molecules. Methuen: London/Wiley: New York, 1964; Chapter 2, pp. 14-15.

23. F. J. Baltá Calleja, C. Santa Cruz, C. Sawatari, T. Asano, Macromolecules, 23, 5352 (1990).

24. L. C. E. Struik, J. Non-Cryst. Solids, 131, 395 (1991).

25. A. Flores, F. J. Baltá Calleja, G. E. Attenburrow, D. C. Bassett, Polymer, 41, $5431(2000)$. 


\section{Figure captions}

Figure 1. Diffractograms of iPP: original, and crosslinked sample 1. The composition is indicated in Table 1.1.

Figure 2. Diffractograms of blends iPP/LDPE 50/50: original, and crosslinked blend IIA. The composition is given in Table 1.2.

Figure 3. Thermograms of iPP: original, and crosslinked samples 1 and 4 . See the composition in Table 1.1.

Figure 4. Thermograms of blends iPP/LDPE 50/50: original, and crosslinked blends IIB and IIE. The composition is shown in Table 1.2

Figure 5. Thermograms of blends iPP/LDPE 70/30: original, and crosslinked blends IV2 and IV5. See the composition in Table 1.2.

Figure 6. Dependence of the microhardness with the iPP content in the samples studied. Compositions are indicated in Tables 1.1 and 1.2. Straight lines 1 and 2: additivity law in unmodified and crosslinked blends. Curves 3 and 5: lines fitted to the hardness behavior shown by the unmodified and crosslinked blends as a function of the iPP content.

Figure 7. Plot showing the fracture behavior of: (a) iPP/LDPE 50/50 crosslinked blend IIE; (b) iPP/LDPE 30/70 crosslinked blend VI6 (See Table 1.2).

Figure 8. Relationship between the elastic modulus and the microhardness in the crosslinked blends. Compositions are indicated in Table 1.2. 
Table 1.1. Composition of iPP and LDPE samples

\begin{tabular}{|c|c|c|c|c|}
\hline Sample & Polymer & $\begin{array}{c}\text { Peroxide content } \\
\%\end{array}$ & $\begin{array}{c}\text { Sulfur content } \\
\%\end{array}$ & $\begin{array}{c}\text { Accelerator content } \\
\%\end{array}$ \\
\hline $\mathrm{iPP}$ & $\mathrm{iPP}$ & --- & -- & --- \\
\hline 1 & $\mathrm{iPP}$ & 0.2 & 0.2 & 0.05 (TMTM) \\
\hline 2 & $\mathrm{iPP}$ & 0.4 & 0.4 & 0.1 (TMTM) \\
\hline 3 & $\mathrm{iPP}$ & 0.2 & 0.2 & 0.05 (TMTD) \\
\hline 4 & $\mathrm{iPP}$ & 0.4 & 0.4 & 0.1 (TMTD) \\
\hline 5 & $\mathrm{iPP}$ & 0.2 & 0.2 & 0.05 (MBTS) \\
\hline 6 & $\mathrm{iPP}$ & 0.4 & 0.4 & 0.1 (MBTS) \\
\hline $\mathrm{LDPE}$ & $\mathrm{LDPE}$ & --- & --- & -- \\
\hline $\mathrm{X} 1$ & $\mathrm{LDPE}$ & 0.2 & 0.2 & 0.05 (TMTM) \\
\hline $\mathrm{X} 2$ & $\mathrm{LDPE}$ & 0.4 & 0.4 & 0.1 (TMTM) \\
\hline $\mathrm{X} 3$ & LDPE & 0.2 & 0.2 & 0.05 (TMTD) \\
\hline $\mathrm{X} 4$ & LDPE & 0.4 & 0.4 & 0.1 (TMTD) \\
\hline $\mathrm{X} 5$ & LDPE & 0.2 & 0.2 & 0.05 (MBTS) \\
\hline $\mathrm{X} 6$ & LDPE & 0.4 & 0.4 & 0.1 (MBTS) \\
\hline
\end{tabular}

Table 1.2. Composition of iPP/LDPE blends

\begin{tabular}{|c|c|c|c|c|}
\hline Sample & Polymer & $\begin{array}{c}\text { Peroxide content } \\
\%\end{array}$ & $\begin{array}{c}\text { Sulfur content } \\
\%\end{array}$ & $\begin{array}{c}\text { Accelerator content } \\
\%\end{array}$ \\
\hline iPP/LDPE 30/70 & iPP/LDPE 30/70 & --- & --- & -- \\
\hline VI1 & iPP/LDPE 30/70 & 0.2 & 0.2 & 0.05 (TMTM) \\
\hline VI2 & iPP/LDPE 30/70 & 0.4 & 0.4 & 0.1 (TMTM) \\
\hline VI3 & iPP/LDPE 30/70 & 0.2 & 0.2 & 0.05 (TMTD) \\
\hline VI4 & iPP/LDPE 30/70 & 0.4 & 0.4 & 0.1 (TMTD) \\
\hline VI5 & iPP/LDPE 30/70 & 0.2 & 0.2 & 0.05 (MBTS) \\
\hline VI6 & iPP/LDPE 30/70 & 0.4 & 0.4 & 0.1 (MBTS) \\
\hline iPP/LDPE 50/50 & iPP/LDPE 50/50 & -- & --- & - \\
\hline IIA & iPP/LDPE 50/50 & 0.2 & 0.2 & 0.05 (TMTM) \\
\hline IIB & iPP/LDPE 50/50 & 0.4 & 0.4 & 0.1 (TMTM) \\
\hline IIC & iPP/LDPE 50/50 & 0.2 & 0.2 & 0.05 (TMTD) \\
\hline IID & iPP/LDPE 50/50 & 0.4 & 0.4 & 0.1 (TMTD) \\
\hline IIE & iPP/LDPE 50/50 & 0.2 & 0.2 & 0.05 (MBTS) \\
\hline IIF & iPP/LDPE 50/50 & 0.4 & 0.4 & 0.1 (MBTS) \\
\hline iPP/LDPE 70/30 & iPP/LDPE 70/30 & --- & --- & - \\
\hline IV1 & iPP/LDPE 70/30 & 0.2 & 0.2 & 0.05 (TMTM) \\
\hline IV2 & iPP/LDPE 70/30 & 0.4 & 0.4 & 0.1 (TMTM) \\
\hline IV3 & iPP/LDPE 70/30 & 0.2 & 0.2 & 0.05 (TMTD) \\
\hline IV4 & iPP/LDPE 70/30 & 0.4 & 0.4 & 0.1 (TMTD) \\
\hline IV5 & iPP/LDPE 70/30 & 0.2 & 0.2 & 0.05 (MBTS) \\
\hline IV6 & iPP/LDPE 70/30 & 0.4 & 0.4 & 0.1 (MBTS) \\
\hline
\end{tabular}


Table 2.1. iPP/LDPE 30/70 blends: Melting points $T_{m P E}$ and $T_{m P P}$ from DSC; crystal thickness values $I_{C P E}$ and $I_{C P P}$ derived from the melting points; melting enthalpies $\triangle H_{P E}$ and $\triangle H_{P P}$; crystallinity values $\alpha_{P E}, \alpha_{P P}$ and $\alpha_{D S C}$ (total) derived from DSC; crystallinity $\alpha_{r X}$ derived from WAXS, microhardness $H$ and impact strength, I.S. Samples are as in Table 1.2.

\begin{tabular}{|c|c|c|c|c|c|c|c|c|c|c|c|c|}
\hline Sample & $\begin{array}{c}\mathrm{T}_{\mathrm{mPE}} \\
\left({ }^{\circ} \mathrm{C}\right)\end{array}$ & $\begin{array}{c}1_{\mathrm{CPE}} \\
(\mathrm{nm})\end{array}$ & $\begin{array}{c}\Delta \mathrm{H}_{\mathrm{PE}} \\
(\mathrm{J} / \mathrm{g})\end{array}$ & $\alpha_{\mathrm{PE}}$ & $\begin{array}{c}\mathrm{T}_{\mathrm{mPP}} \\
\left({ }^{\circ} \mathrm{C}\right)\end{array}$ & $\begin{array}{c}\mathrm{l}_{\mathrm{cPP}} \\
(\mathrm{nm})\end{array}$ & $\begin{array}{c}\Delta \mathrm{H}_{\mathrm{PP}} \\
(\mathrm{J} / \mathrm{g})\end{array}$ & $\alpha_{\mathrm{PP}}$ & $\begin{array}{c}\alpha_{\mathrm{DSC}} \\
(\mathrm{total})\end{array}$ & $\alpha_{\mathrm{rX}}$ & $\begin{array}{c}\mathrm{H} \\
(\mathrm{MPa})\end{array}$ & $\begin{array}{c}\mathrm{I} . \mathrm{S} . \\
\left(\mathrm{kJ} / \mathrm{m}^{2}\right)\end{array}$ \\
\hline $\begin{array}{c}\text { iPP/LDPE } \\
30 / 70\end{array}$ & 109.5 & 6.9 & 72.0 & 0.24 & 160.6 & 17.3 & 21.0 & 0.10 & 0.35 & 0.39 & 30 & 3.45 \\
\hline VI1 & 112.8 & 7.7 & 89.4 & 0.30 & 159.1 & 16.4 & 20.9 & 0.10 & 0.40 & 0.40 & 29 & 24.04 \\
\hline VI2 & 112.9 & 7.8 & 98.1 & 0.33 & 159.3 & 16.5 & 23.2 & 0.11 & 0.45 & 0.41 & 30 & 19.09 \\
\hline VI3 & 112.7 & 7.7 & 94.9 & 0.32 & 159.2 & 16.5 & 23.1 & 0.11 & 0.43 & 0.41 & 30 & 15.36 \\
\hline VI4 & 114.1 & 7.7 & 100.9 & 0.34 & 159.8 & 16.8 & 23.7 & 0.11 & 0.46 & 0.39 & 28 & 11.86 \\
\hline VI5 & 112.2 & 7.6 & 102.2 & 0.35 & 160.7 & 17.4 & 26.7 & 0.13 & 0.48 & 0.37 & 32 & 34.12 \\
\hline VI6 & 112.4 & 7.6 & 103.6 & 0.35 & 158.8 & 16.2 & 24.1 & 0.11 & 0.47 & 0.40 & 29 & 31.81 \\
\hline
\end{tabular}

Table 2.2. iPP/PE 50/50 blends: Melting points $T_{m P E}$ and $T_{m P P}$ from DSC; crystal thickness values $I_{C P E}$ and $I_{C P P}$ derived from the melting points; melting enthalpies $\triangle H_{P E}$ and $\Delta H_{P P}$; crystallinity values $\alpha_{P E}, \alpha_{P P}$ and $\alpha_{D S C}$ (total) derived from DSC; crystallinity $\alpha_{r X}$ derived from WAXS, and microhardness $H$. Samples are as in Table 1.2.

\begin{tabular}{|c|c|c|c|c|c|c|c|c|c|c|c|c|}
\hline Sample & $\begin{array}{c}\mathrm{T}_{\mathrm{mPE}} \\
\left({ }^{\circ} \mathrm{C}\right)\end{array}$ & $\begin{array}{c}\mathrm{l}_{\mathrm{cPE}} \\
(\mathrm{nm})\end{array}$ & $\begin{array}{c}\Delta \mathrm{H}_{\mathrm{PE}} \\
(\mathrm{J} / \mathrm{g})\end{array}$ & $\alpha_{\mathrm{PE}}$ & $\begin{array}{c}\mathrm{T}_{\mathrm{mPP}} \\
\left({ }^{\circ} \mathrm{C}\right)\end{array}$ & $\begin{array}{c}\mathrm{l}_{\mathrm{CPP}} \\
(\mathrm{nm})\end{array}$ & $\begin{array}{c}\Delta \mathrm{H}_{\mathrm{PP}} \\
(\mathrm{J} / \mathrm{g})\end{array}$ & $\alpha_{\mathrm{PP}}$ & $\begin{array}{c}\alpha_{\mathrm{DSC}} \\
(\text { total })\end{array}$ & $\alpha_{\mathrm{rX}}$ & $\begin{array}{c}\mathrm{H} \\
(\mathrm{MPa})\end{array}$ & $\begin{array}{c}\text { I.S. } \\
\left(\mathrm{kJ} / \mathrm{m}^{2}\right)\end{array}$ \\
\hline $\begin{array}{c}\mathrm{iPP} / \mathrm{LDPE} \\
50 / 50\end{array}$ & 108.8 & 6.8 & 50.3 & 0.17 & 157.7 & 15.6 & 49.7 & 0.24 & 0.41 & 0.44 & 33 & 4.42 \\
\hline IIA & 112.3 & 7.6 & 79.6 & 0.27 & 158.8 & 16.3 & 36.7 & 0.18 & 0.45 & 0.43 & 39 & 7.32 \\
\hline IIB & 111.9 & 7.5 & 72.2 & 0.25 & 159.0 & 16.4 & 36.2 & 0.17 & 0.42 & 0.45 & 37 & 6.67 \\
\hline IIC & 112.4 & 7.6 & 74.8 & 0.25 & 159.6 & 16.7 & 35.7 & 0.17 & 0.43 & 0.46 & 40 & --- \\
\hline IID & 111.9 & 7.5 & 71.2 & 0.24 & 157.3 & 15.5 & 35.2 & 0.17 & 0.41 & 0.43 & 34 & 5.36 \\
\hline IIE & 112.5 & 7.6 & 73.4 & 0.25 & 160.2 & 17.1 & 37.3 & 0.18 & 0.43 & 0.43 & 41 & 5.90 \\
\hline IIF & 111.5 & 7.4 & 82.6 & 0.28 & 158.2 & 15.9 & 37.3 & 0.18 & 0.46 & 0.42 & 34 & 7.19 \\
\hline
\end{tabular}


Table 2.3. iPP/PE $70 / 30$ blends: Melting points $T_{m P E}$ and $T_{m P P}$ from DSC; crystal thickness values $I_{C P E}$ and $I_{C P P}$ derived from the melting points; melting enthalpies $\triangle H_{P E}$ and $\triangle H_{P P}$; crystallinity values $\alpha_{P E}, \alpha_{P P}$ and $\alpha_{D S C}$ (total) derived from DSC; crystallinity $\alpha_{r X}$ derived from WAXS, and microhardness $H$. Samples are as in Table 1.2.

\begin{tabular}{|c|c|c|c|c|c|c|c|c|c|c|c|c|}
\hline Sample & $\begin{array}{c}\mathrm{T}_{\mathrm{mPE}} \\
\left({ }^{\circ} \mathrm{C}\right)\end{array}$ & $\begin{array}{c}\mathrm{l}_{\mathrm{cPE}} \\
(\mathrm{nm})\end{array}$ & $\begin{array}{c}\Delta \mathrm{H}_{\mathrm{PE}} \\
(\mathrm{J} / \mathrm{g})\end{array}$ & $\alpha_{\mathrm{PE}}$ & $\begin{array}{c}\mathrm{T}_{\mathrm{mPP}} \\
\left({ }^{\circ} \mathrm{C}\right)\end{array}$ & $\begin{array}{c}1_{\mathrm{cPP}} \\
(\mathrm{nm})\end{array}$ & $\begin{array}{c}\Delta \mathrm{H}_{\mathrm{PP}} \\
(\mathrm{J} / \mathrm{g})\end{array}$ & $\alpha_{\mathrm{PP}}$ & $\begin{array}{c}\alpha_{\mathrm{DSC}} \\
(\text { total })\end{array}$ & $\alpha_{\mathrm{rX}}$ & $\begin{array}{c}\mathrm{H} \\
(\mathrm{MPa})\end{array}$ & $\begin{array}{c}\text { I.S. } \\
\left(\mathrm{kJ} / \mathrm{m}^{2}\right)\end{array}$ \\
\hline $\begin{array}{c}\mathrm{iPP} / \mathrm{LDPE} \\
70 / 30\end{array}$ & 109.2 & 6.9 & 40.1 & 0.14 & 158.7 & 16.2 & 61.4 & 0.30 & 0.43 & 0.43 & 45 & 2.58 \\
\hline IV1 & 111.4 & 7.4 & 73.6 & 0.25 & 158.6 & 16.2 & 54.1 & 0.26 & 0.51 & 0.44 & 49 & 5.91 \\
\hline IV2 & 111.2 & 7.3 & 56.4 & 0.19 & 161.0 & 17.6 & 59.9 & 0.29 & 0.48 & 0.45 & 51 & 6.09 \\
\hline IV3 & 110.8 & 7.2 & 63.0 & 0.21 & 159.7 & 16.8 & 53.9 & 0.26 & 0.47 & 0.44 & 53 & 4.28 \\
\hline IV4 & 111.1 & 7.3 & 58.0 & 0.20 & 159.2 & 16.5 & 55.2 & 0.27 & 0.46 & 0.44 & 52 & 5.74 \\
\hline IV5 & 111.3 & 7.3 & 65.6 & 0.22 & 159.4 & 16.6 & 49.2 & 0.24 & 0.46 & 0.49 & 44 & 5.60 \\
\hline IV6 & 110.7 & 7.2 & 57.4 & 0.20 & 159.5 & 16.6 & 57.0 & 0.27 & 0.47 & 0.47 & 59 & 7.03 \\
\hline
\end{tabular}

Table 2.4. Mechanical properties of the crosslinked blends (tensile stress-strain study). Samples are as in Table 1.2.

\begin{tabular}{|c|c|c|c|c|}
\hline Sample & $\begin{array}{c}\text { Elastic modulus } \\
(\mathrm{MPa})\end{array}$ & $\begin{array}{c}\text { Stress at break } \\
(\mathrm{MPa})\end{array}$ & $\begin{array}{c}\text { Strain at Break } \\
(\%)\end{array}$ & $\begin{array}{c}\text { Energy at break } \\
(\mathrm{J})\end{array}$ \\
\hline VI1 & 355 & 16.55 & 10.3 & 5.1 \\
\hline VI2 & 375 & 17.2 & 8.8 & 4.4 \\
\hline VI3 & 332 & 12.9 & 13.5 & 7.0 \\
\hline VI4 & 458 & 17.6 & 13.2 & 7.6 \\
\hline VI5 & 390 & 17.5 & 15.9 & 9.8 \\
\hline VI6 & 490 & 18.0 & 14.8 & 9.2 \\
\hline IIA & 603 & 22.3 & 9.5 & 6.2 \\
\hline IIB & 690 & 22.5 & 12.5 & 10.5 \\
\hline IIC & 614 & 21.0 & 7.9 & 4.8 \\
\hline IID & 650 & 22.6 & 10.6 & 7.5 \\
\hline IIE & 667 & 22.0 & 9.4 & 6.1 \\
\hline IIF & 976 & 26.4 & 9.4 & 8.0 \\
\hline IV1 & 1050 & 27.0 & 8.3 & 6.8 \\
\hline IV2 & 966 & 56.6 & 10.7 & 9.3 \\
\hline IV3 & 845 & 25.4 & 10.1 & 8.4 \\
\hline IV4 & 3638 & 105.8 & 8.4 & 7.1 \\
\hline IV5 & 960 & 25.9 & 9.4 & 7.81 \\
\hline IV6 & 976 & 26.4 & 9.4 & 8.0 \\
\hline
\end{tabular}




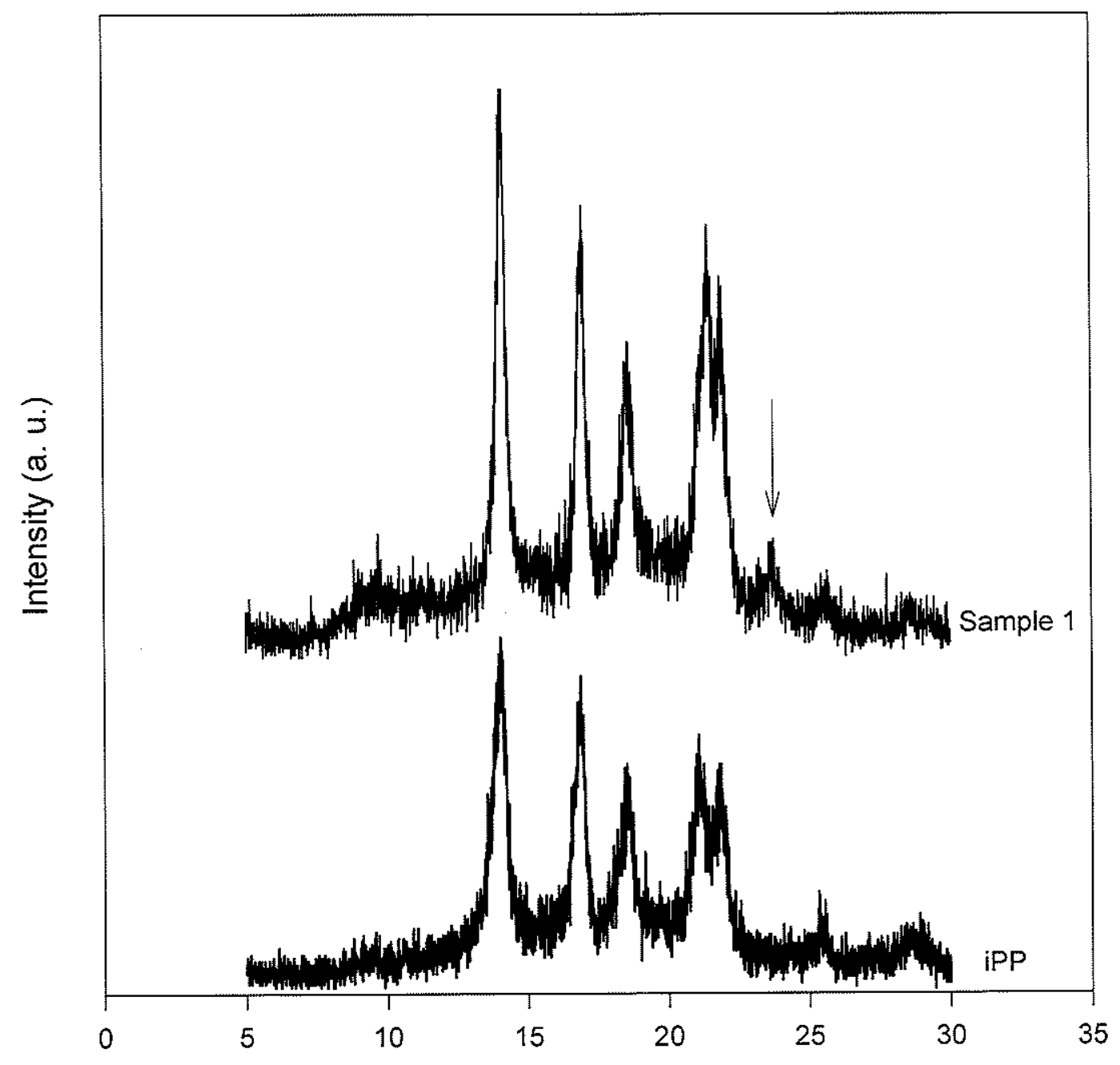

Fig. 1 


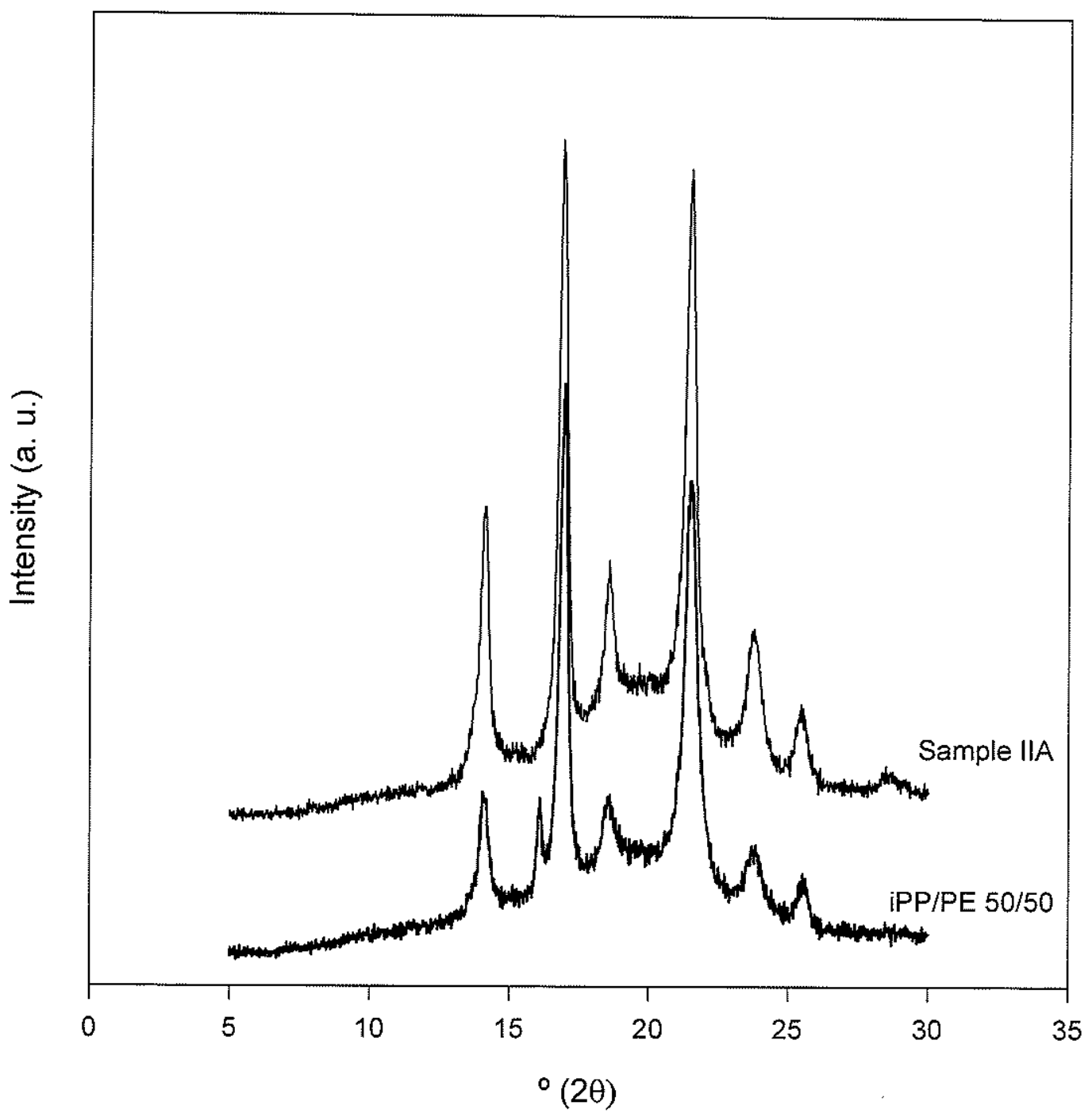

Fig. 2 


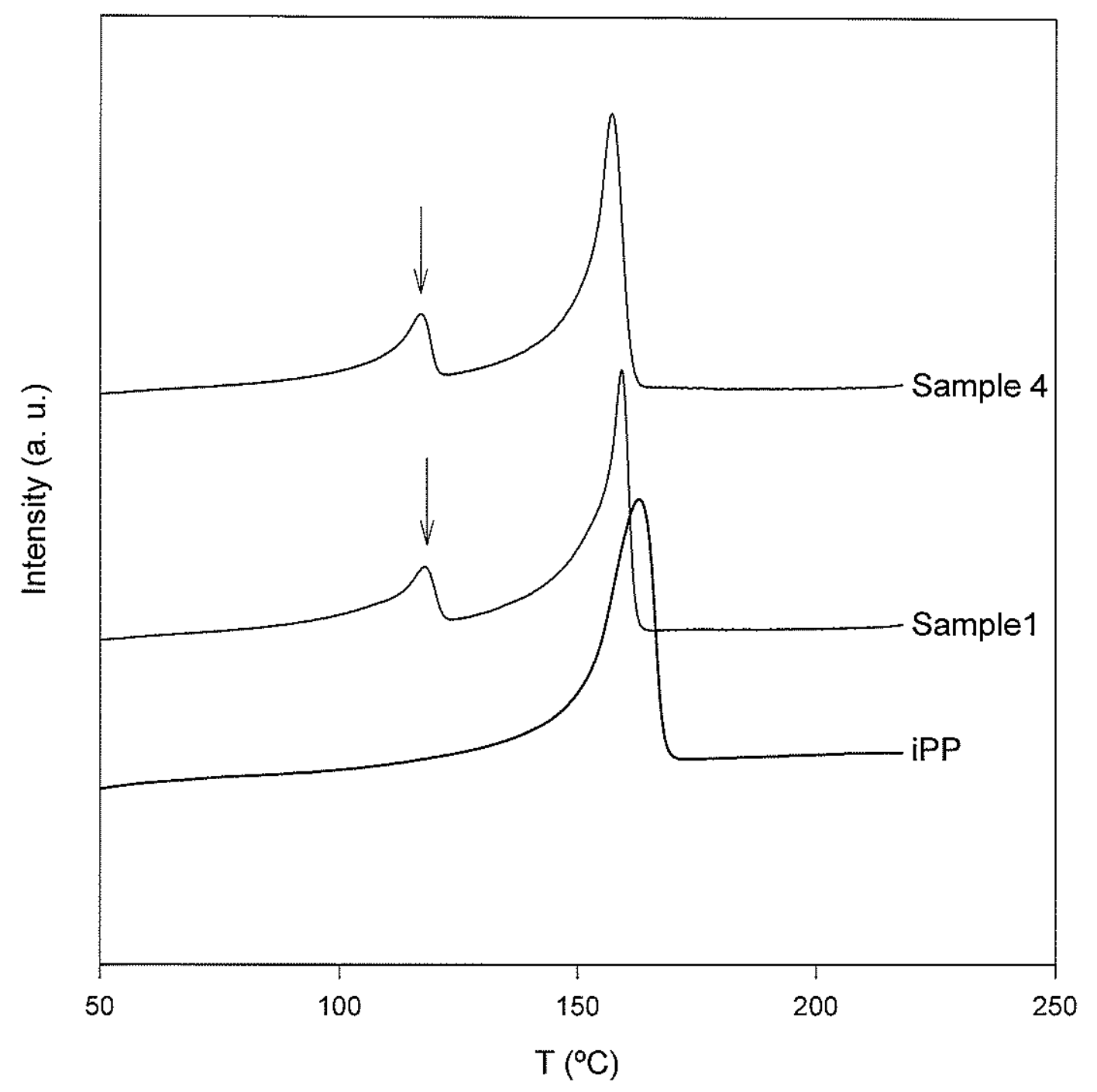

Fig. 3 


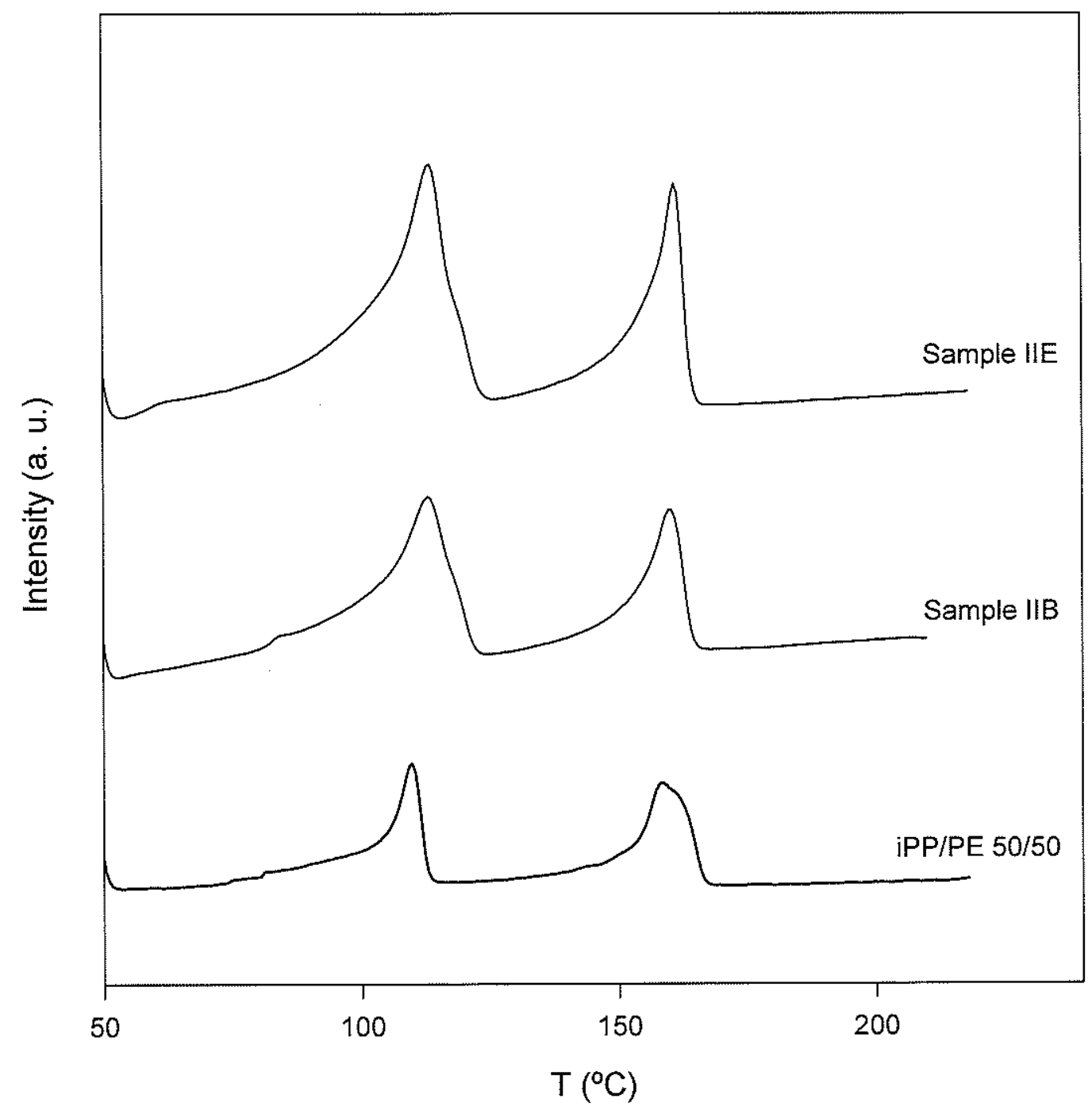

Fig. 4 


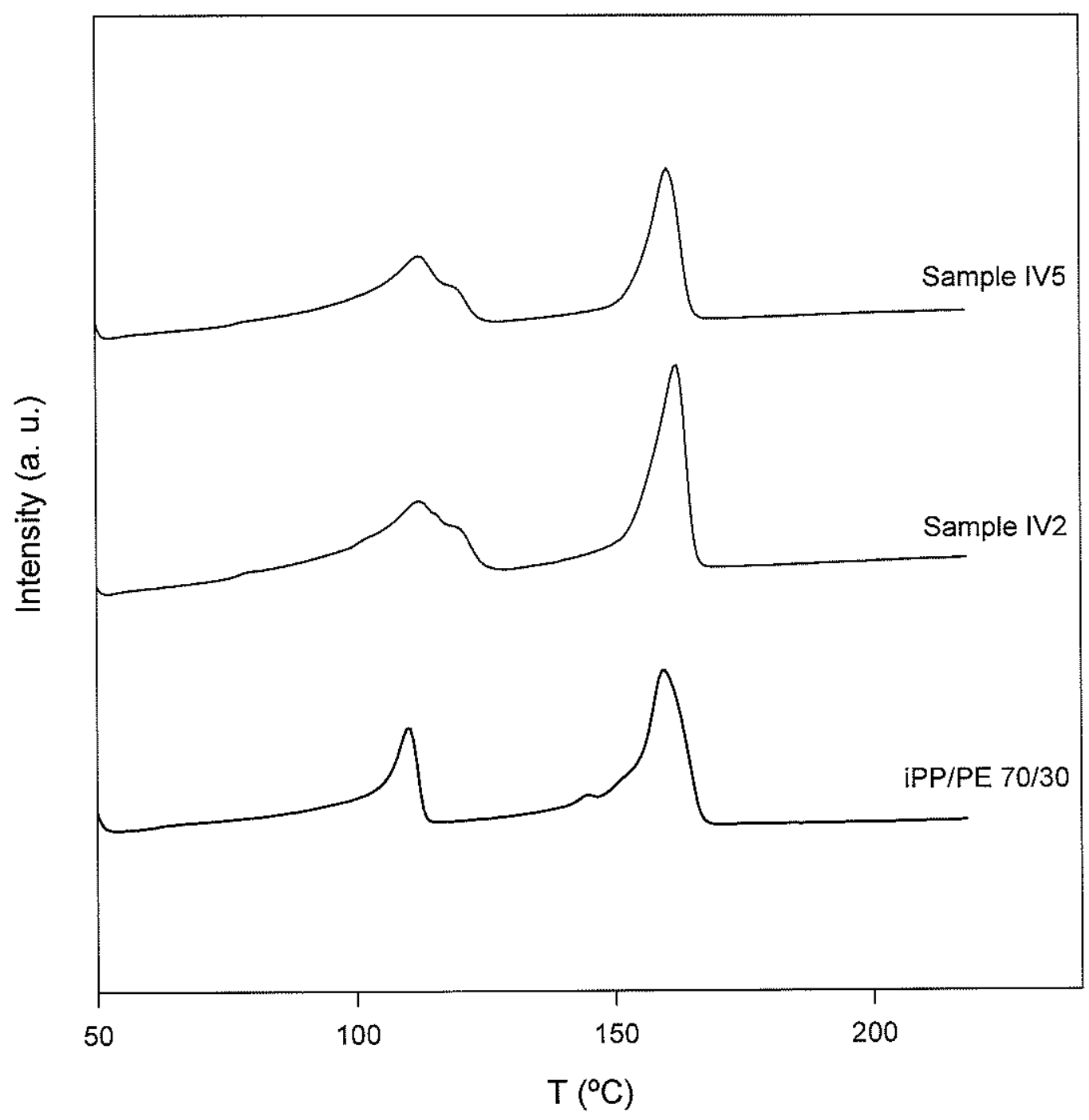

Fig. 5 


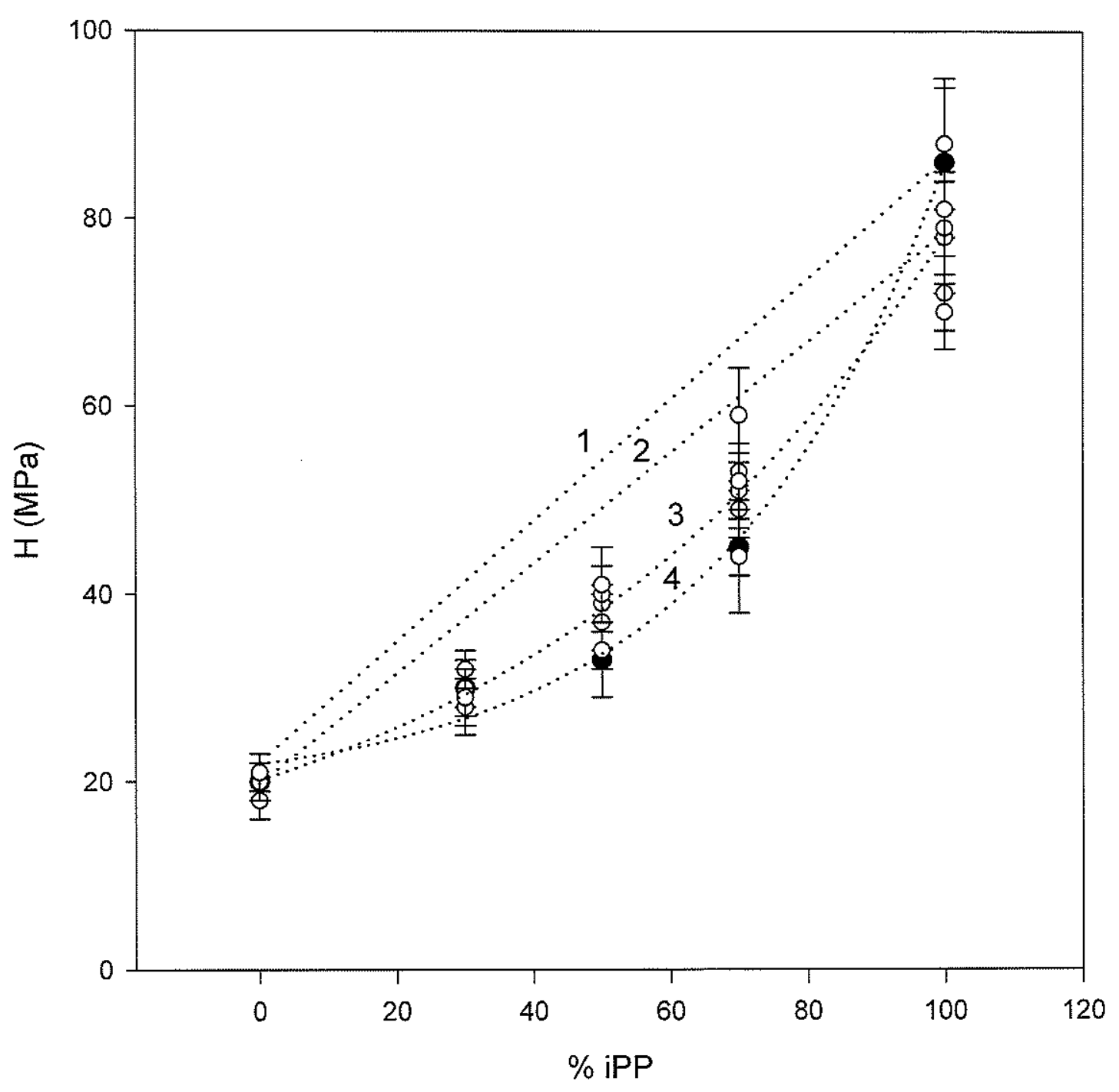

Fig. 6 


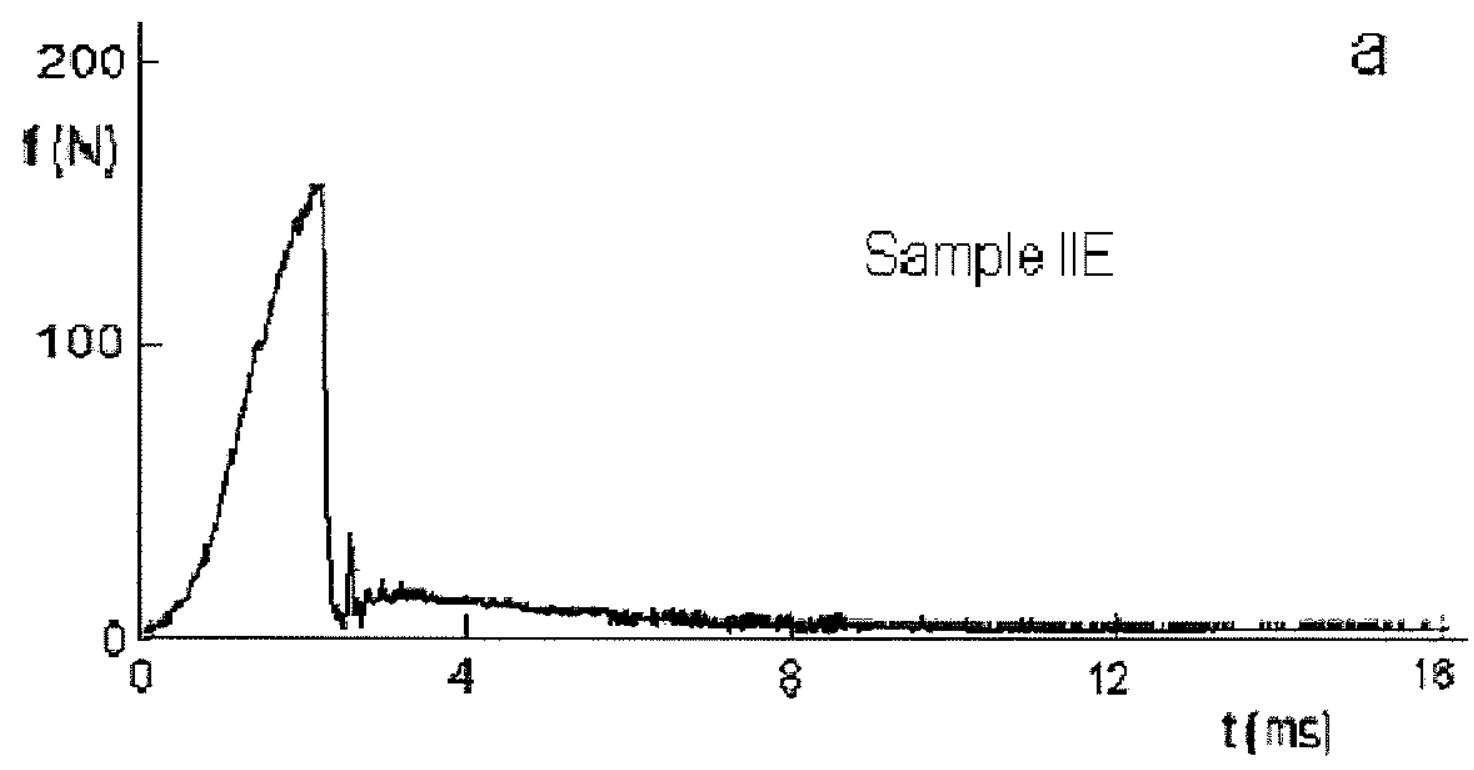

b

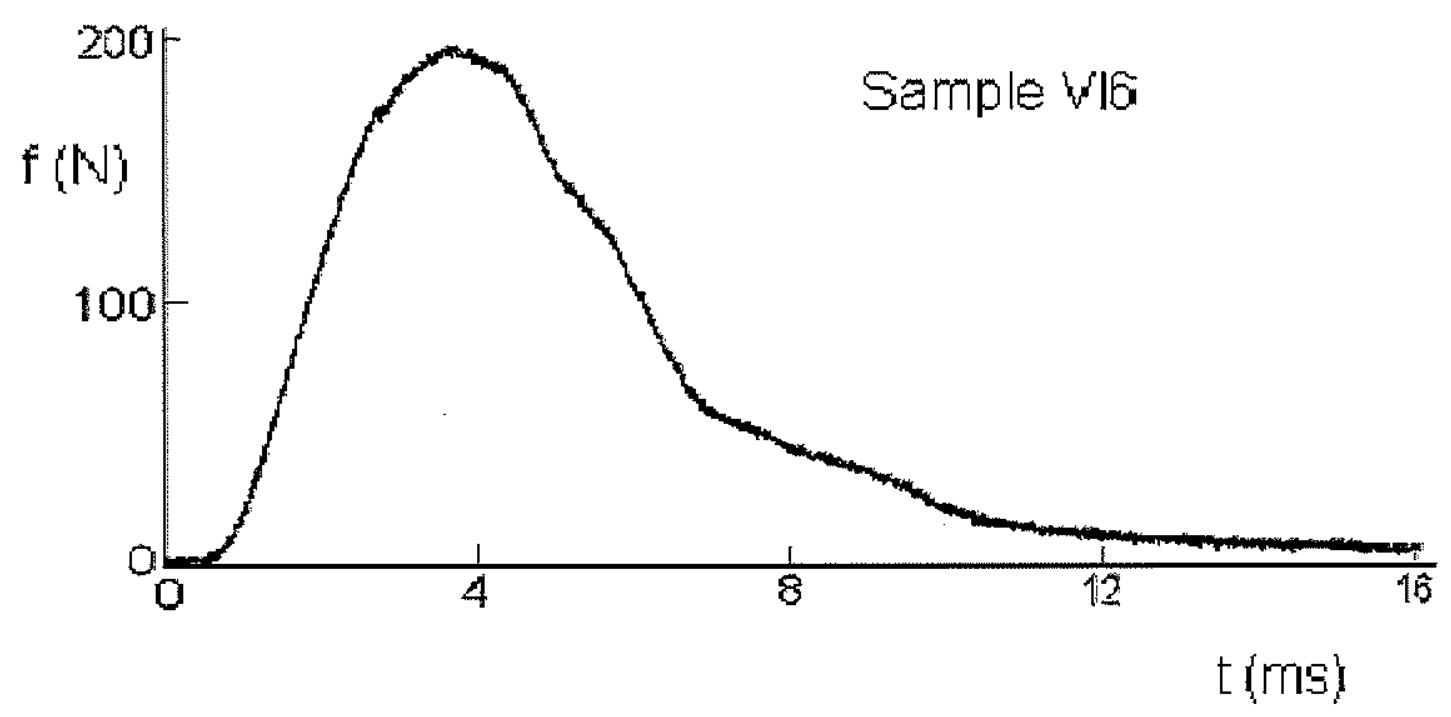

Fig. 7 


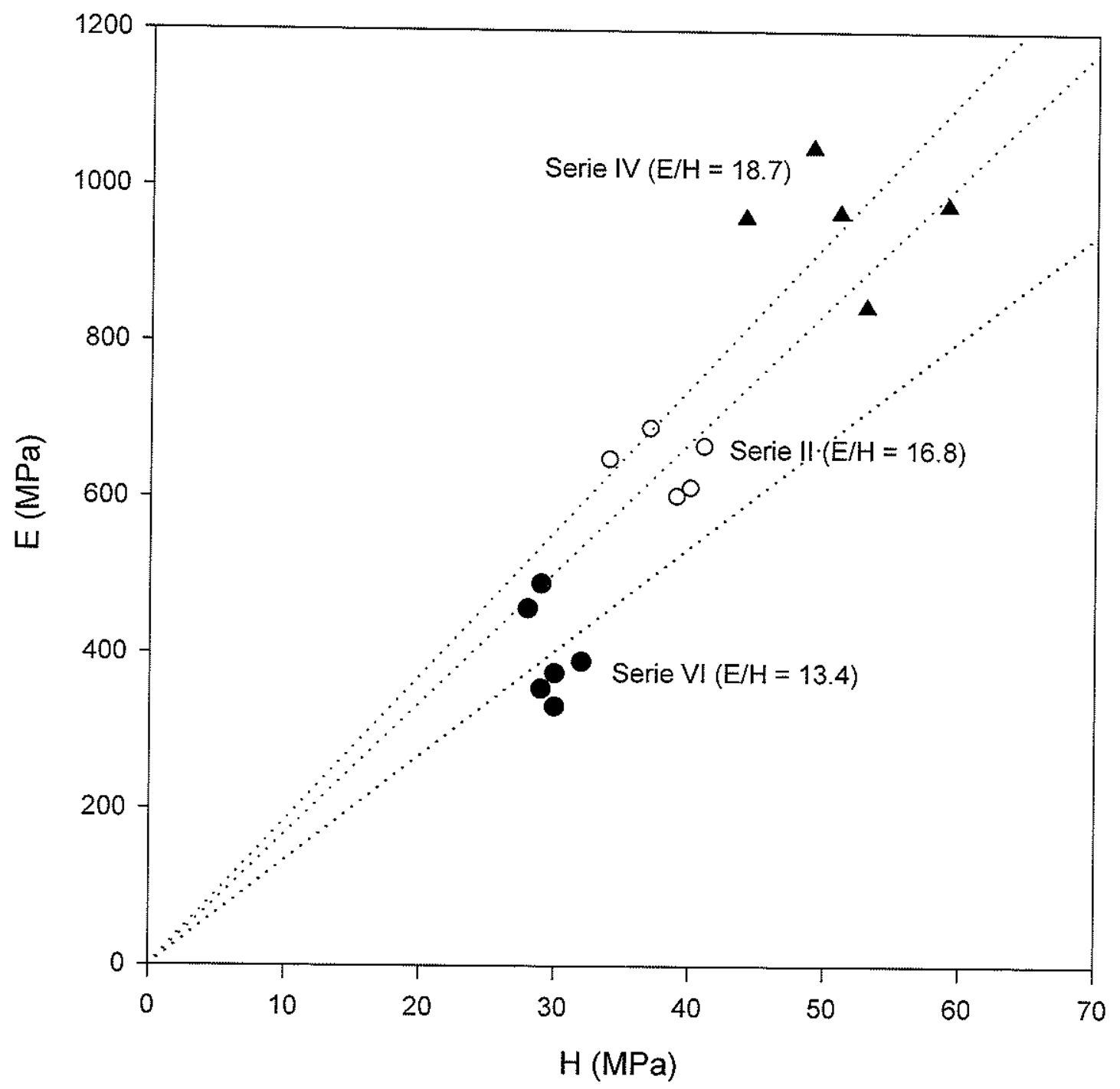

Fig. 8 